\title{
TREATMENT OF THE SCHOENLEIN-HENOCH SYNDROME WITH ADRENOCORTICOTROPHIC HORMONE (A.C.T.H.) AND CORTISONE
}

\author{
BY \\ M. G. PHILPOTT and J. N. BRIGGS \\ From the Children's Hospital, Sheffield, and the Department of Child Health, University of Sheffield
}

(RECEIVED FOR PUBLICATION AUGUST 22, 1952)

It has been shown that a relationship exists between the Schoenlein-Henoch syndrome and diseases such as acute nephritis, rheumatic fever and polyarteritis nodosa (Gairdner, 1948). In view of this relationship, it seemed reasonable to try the effect of adrenocorticotrophic hormone (A.C.T.H.) and cortisone on the course of this disease. It was hoped also that these hormones might reduce the incidence of glomerulonephritis, which was found by Philpott (1952) in $47.5 \%$ of 40 cases in children studied, and which is considered the most dangerous complicating feature of this syndrome.

Only a few reports have appeared in the literature on the treatment of the Schoenlein-Henoch syndrome with A.C.T.H. and cortisone. Stefanini, Roy, Zannos and Dameshek (1950) treated one case with A.C.T.H. Although this patient's general condition improved remarkably, there were further attacks of purpura while the patient was being treated and a relapse of all symptoms occurred when it was stopped. Nephrieis, which was present before starting the A.C.T.H., deteriorated while under treatment. Woolley (1952) reported a case treated with A.C.T.H. in which further symptoms occurred while under treatment and pre-existing nephritis deteriorated. Kugelmass (1951) reported four cases treated with cortisone and was enthusiastic about its value. He did not state, however, how frequent or how complete were the urinalyses in these cases, and did not make clear how long these patients were under surveillance. Kugelmass admitted that 'mild manifestations' might continue for weeks after the withdrawal of the drugs.

We have treated nine children with the SchoenleinHenoch syndrome with A.C.T.H. or cortisone or both. The results are presented, two cases being reported in full and summaries given of the remaining seven.

\section{Case Reports}

Case 1. The patient, a girl, was aged 5 years in March, 1951. For five days she had had swollen joints and a rash for four days with colicky abdominal pain and blood in the stools. The rash was typical of the Schoenlein-Henoch syndrome but there was no arthritis on admission. For 12 days she continued to pass bloody stools and further crops of skin lesions appeared. Intramuscular injection of A.C.T.H. was then started and continued for 25 days, a total of $475 \mathrm{mg}$. being given. The eosinophil count was always too low to assess any depression during treatment. The child's general condition rapidly improved on treatment and the intestinal bleeding ceased in two days. Several crops of skin lesions appeared during the first week of treatment, after which all symptoms ceased. The urine showed evidence of acute nephritis on the day A.C.T.H. treatment was begun. She still has evidence of nephritis but there have been no further symptoms.

Case 2. A boy, aged 3 years in May, 1951, had otitis media six weeks before admission. During the succeeding weeks this was followed by periodic swellings of the joints and a rash which was most marked over the buttocks and limbs. During the last 10 days before admission he had been passing frank blood per rectum as well as melaena stools. He was admitted on May 9, 1951.

On admission he appeared a well nourished, slightly febrile child (99: F.) not acutely ill. A papulo-purpuric rash was present on the face, buccal mucosa, buttocks, arms and legs. He had a small subconjunctival haemorrhage in the left eye. The left elbow and wrist were slightly swollen and tender. He also had acute tonsillitis and a right submental abscess. He passed a melaena stool shortly after admission.

Haemoglobin was 10.0 g. ${ }_{0}{ }_{0}$ : platelets, 450,000 per c.mm. Capillary fragility was positive at $-250 \mathrm{~mm}$. $\mathbf{H g}$. Blood pressure was $106 / 70 \mathrm{~mm}$. $\mathrm{Hg}$. The erythrocyte sedimentation rate was $8 \mathrm{~mm}$. in one hour.

The child was given intramuscular penicillin and the right submental abscess was incised. On May 11 fresh petechiae appeared on the arms and he complained of central abdominal pain. He passed several stools containing frank blood. Treatment with A.C.T.H. was begun in a dose of $10 \mathrm{mg}$. six-hourly. On May 13 he was much livelier, the rash was fading and the stools were macroscopically normal. The eosinophil count had fallen from 27 to 2 per c.mm. by the end of five days. Six days later, on May 17. a new batch of A.C.T.H. was begun and the 
dose was reduced to $5 \mathrm{mg}$. six-hourly. On May 19, associated with a strongly positive Mantoux reaction (O.T. 1 1000), fresh skin lesions appeared. The batch of A.C.T.H. was altered and the dose was increased to $10 \mathrm{mg}$. six-hourly, but further petechiae continued to appear. The drug was continued until May 26. He received a total course of $570 \mathrm{mg}$. Subsequently it was shown that the batch of A.C.T.H. used from May 17 to May 26 may have been inactive as it failed to produce any eosinophil response in a control case. During the subsequent three months without treatment the patient continued to have further skin eruptions.

On admission the boy's urine and E.S.R. were normal. On May 22, following an exacerbation of the purpura, protein $\left(250 \mathrm{mg} .{ }^{\circ}\right)$ appeared in the urine and red blood cells and granular and cellular casts were seen. The urinary changes persisted for 10 weeks and then gradually returned to normal. The E.S.R. was raised during this time, but subsequently became normal. His blood pressure was never higher than $120 / 75 \mathrm{~mm}$. Hg. An Addis count on February 22, 1952, was within normal limits. He is being observed as an out-patient and remains clinically well.

Case 3. A boy, aged 10 years in April, 1951, had abdominal pain for five weeks and for four weeks swollen joints and a rash. On admission he had the typical rash of the Schoenlein-Henoch syndrome, blood in the stools, and the right wrist was swollen. His general condition was very good, but the E.S.R. was $30 \mathrm{~mm}$. in one hour and the urine showed evidence of acute nephritis. Intramuscular A.C.T.H. was started on the day after admission, producing a good eosinophil response. The intestinal bleeding and arthritis subsided, and no fresh skin lesions appeared for 10 days, when an extensive crop was produced. This coincided with the use of a new batch of A.C.T.H. which, it was considered, might be inactive (see Case 2). In 14 days $440 \mathrm{mg}$. of A.C.T.H. had been given, and, as fresh skin lesions were still appearing, treatment was altered to cortisone which was given for five days (total $500 \mathrm{mg}$.). There were no further symptoms during treatment but he has had several attacks of purpura since. The nephritis was unaffected by treatment and is still present.

Case 4. A girl, aged 6 years in October, 1951, for two days had had swollen joints and a rash for one day. On admission, she was ill, had the typical rash, and the left wrist and both elbows were swollen. A.C.T.H. was given intramuscularly for a week (total $315 \mathrm{mg}$.) without any eosinophil depression. Her general condition slowly improved and the arthritis subsided in two days and did not recur. Further skin lesions appeared almost daily for two weeks, after which there were no further symptoms. After another three weeks she was found to have acute nephritis but this subsided in a further three weeks, the final Addis count being normal. She has remained well since.

Case 5. A boy, aged 2 years in November, 1951, suffered an attack of rash and swollen joints in August, 1951, lasting 10 weeks. After four weeks' freedom the symptoms recurred and he was admitted on the fourth day of the relapse. He was ill, and had an extensive maculo-papulo-petechial rash and subconjunctival haemorrhages, but there was no arthritis. Further skin lesions appeared for a week when a stool contained blood. At this stage intramuscular A.C.T.H. was started and given for six days (total $480 \mathrm{mg}$.). His general condition improved slowly but two days after starting treatment a further bloody stool was passed and more skin lesions appeared. After this there were no further symptoms. The eosinophil response was not studied in this case. He has remained well since and there has been no evidence of nephritis.

Case 6. A girl, aged 33 years in November, 1951, had had for nine days a rash and swollen joints. On the day before admission she passed a bloody stool and vomited. On admission she was ill, and had the typical rash but no arthritis. Intramuscular A.C.T.H. was started on the day after admission and continued for six days (total 480 mg.). A satisfactory eosinophil response was obtained. Her general condition rapidly improved and she had no further symptoms. The urine was at no time abnormal. She has remained well since.

Case 7. A boy, aged $10 \pm$ years in January, 1952, had had a rash and swollen joints for eight days. He had had severe abdominal pain without blood in the stools for the first two days of the illness. On admission he was ill and in considerable pain from arthritis. Both knees and ankles were swollen and he had an extensive maculopapulo-petechial rash. Intramuscular A.C.T.H. was started on the day of admission and continued for six days (total $480 \mathrm{mg}$.). The eosinophil count was always too low to assess any depression. No further skin lesions appeared during treatment and the existing arthritis rapidly subsided. His general condition rapidly improved, but on the day after starting treatment the right wrist became swollen and two days later the left wrist also became involved. Both subsided in 48 hours. Further skin lesions appeared, associated with some abdominal pain, on the day after A.C.T.H. therapy was discontinued. He had no further symptoms and has remained well since. At no time has the urine shown any abnormality.

Case 8. A girl, aged 2 years in January, 1952, came to hospital with a four-day history of a rash appearing over the extensor surfaces of the limbs and over the buttocks. Three days before admission areas in the centres of the spots appeared to ulcerate. One day before admission she passed fresh blood per rectum. On the day of admission (January 20, 1952), the arms and legs became swollen, and she was unable to stand.

On admission she was an extremely ill child with a fever of $101 \cdot 8^{=} \mathrm{F}$. with a severe papulo-purpuric rash over the face, buttocks, arms and legs with ulceration of the centres of some of the larger lesions, especially those on the buttocks with many petechiae between the larger lesions. The elbow, knee and ankle joints were painful and swollen; the metacarpal and interphalangeal joints were also swollen. There was some oedema of the right eyelid, and pitting oedema of the upper and lower limbs. Apart from tachycardia $(140 / \mathrm{min}$.) no other abnormality was detected. 
Haemoglobin was $9 \cdot 1 \mathrm{~g} .{ }^{\circ}$, white blood cells were $23,000 / \mathrm{c} . \mathrm{mm}$. and platelets $360,000 / \mathrm{c} . \mathrm{mm}$. The erythrocyte sedimentation rate was $8 \mathrm{~mm}$. in one hour. The blood pressure was not recorded. A blood culture was negative.

On the day after admission the eyelids and joints were more swollen. She was extremely ill and lethargic. Treatment with A.C.T.H. was begun on January 22. The first four doses were $25 \mathrm{mg}$. given at six-hourly intervals. The effect on the eosinophil count could not be recorded as this count was never greater than 1 per c.mm. Thereafter $10 \mathrm{mg}$. were given six-hourly. She received a total of $300 \mathrm{mg}$. in six days. Four hours after A.C.T.H. was begun the eyelids were so oedematous that they were completely closed, and she appeared moribund (Fig. 1). Her temperature was 104 F. Her condition

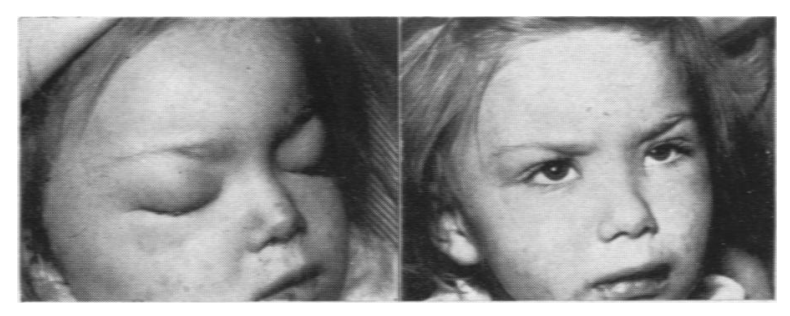

FK. 1

FK. 2

was worse than on admission, for although the joint swellings were slightly less marked, the oedema of the eyelids had increased and there was oedema of the face and neck. Twenty-four hours later there was a marked improvement: the rash was fading, the swellings of the joints had gone, and the facial oedema was lessening. On January 24 she was sitting up playing with toys, and on January 26 the face was normal (Fig. 2). On this day, however, she again became miserable, and slight oedema of the legs and arms reappeared. There was no return of the arthritis. Further petechiae appeared on January 27. but no further frank blood was seen in the stools.

Cortisone. $12 \cdot 5 \mathrm{mg}$. intramuscularly six-hourly, was started on January 27 and continued for 10 days (total $500 \mathrm{mg}$.). After the first 24 hours no marked improvement was noted and not until January 30 did the oedema subside once more. From then on she made an uninterrupted recovery. No further rash. joint swellings or oedema developed while she was on cortisone and there were no relapses after discontinuing treatment. She was discharged on February 15, 1952, and out-patient surveillance has been continued.

On admission the urine was normal. On January 24 it contained $70 \mathrm{mg}$. ${ }_{o}$ of protein, 4-6 red blood cells per high power field and granular casts. Since then repeated specimens have been normal. The E.S.R. has never been raised above $12 \mathrm{~mm}$. in one hour and the blood pressure has remained normal.

Case 9. A girl, aged 7 years in January, 1952, had abdominal pain, swollen joints and a rash for four days. On admission, she was not acutely ill. She had an extensive rash and arthritis involving both wrists and ankles and the right elbow. Cortisone was started two days after admission, $120 \mathrm{mg}$. being given orally in the first 24 hours, followed by $460 \mathrm{mg}$. intramuscularly during the subsequent six days. A satisfactory eosinophil response was produced. Her condition improved over the following two days and the rash and arthritis subsided but after another two days she had a further bout of abdominal pain and fresh skin lesions appeared. At the same time the urine showed evidence of acute nephritis. Since then she has had no further symptoms, but she has persistent proteinuria and the E.S.R. remains elevated.

\section{Discussion}

In this series of cases six were given A.C.T.H. alone, and two received A.C.T.H. followed by cortisone because of relapses. One case was given cortisone alone. The potency of the hormones was judged by the response of the circulating eosinophils and seems to have been adequate in most cases. In only one case was no fall encountered, but the count was too low to assess any fall in three cases. The response was not studied in one case. The results of treatment are summarized in Table 1.

The effect of the hormones on the general condition was assessed by the recovery of well-being, the disappearance of irritability and the return of appetite. Five patients showed considerable improvement within 48 hours, and three more improved more slowly. One patient (Case 3) was not sufficiently unwell to assess any change in the general condition. The constitutional upset during the Schoenlein-Henoch syndrome may be severe, and in Case 8 caused considerable alarm. A rapid improvement was seen on A.C.T.H. therapy, only to be followed by a relapse. Improvement in these cases may have been due to the hormones, but similar improvement can occur spontaneously.

Six cases presented joint swellings and in five the swelling subsided within three days of starting treatment. In one case joint swellings recurred during treatment. Intestinal bleeding occurred in six cases but was seen in only one case after starting hormone therapy. In the natural course of the disease in children, however, joint swellings and intestinal bleeding seldom recur (Philpott, 1952), and the hormones, therefore, were of doubtful value.

The skin manifestations recurred in eight cases during treatment. One batch of A.C.T.H. used in Cases 2 and 3 was thought to be inactive, but further skin lesions appeared in both cases after changing the batch in one and giving cortisone instead in the other. The hormones were, therefore, useless in preventing these manifestations.

The diagnosis of nephritis was made on persistently finding protein, red blood cells and casts in the urine. One patient developed this complication before treatment and in another it was discovered 
TABLE 1

EFFECTS OF TREATMENT WITH A.C.T.H. AND CORTISONE IN THE SCHOENLEIN-HENOCH SYNDROME

\begin{tabular}{|c|c|c|c|c|c|c|c|}
\hline \multirow{2}{*}{ Case } & \multirow{2}{*}{ Treatment } & \multicolumn{3}{|c|}{ Efiects of Treatment } & & \multicolumn{2}{|c|}{ Nephritis } \\
\hline & & $\begin{array}{c}\text { General } \\
\text { Improvement }\end{array}$ & Joint Swelling & $\begin{array}{l}\text { Intestinal } \\
\text { Bleeding }\end{array}$ & Rash & $\begin{array}{c}\text { Before } \\
\text { Treatment }\end{array}$ & $\underset{\text { Treatment }}{\text { After }}$ \\
\hline 1 & A.C.T.H. & Rapid & $\begin{array}{l}\text { Present before admission; ab- } \\
\text { sent on admission; no recur- } \\
\text { rence }\end{array}$ & No recurrence & Recurred & Present & Present \\
\hline 2 & A.C.T.H. & Rapid & Subsided; no recurrence & No recurrence & Recurred & Absent & Present \\
\hline 3 & $\begin{array}{l}\text { A.C.T.H. and } \\
\text { Cortisone }\end{array}$ & Not assessed & Subsided; no recurrence & No recurrence & Recurred & Present & Present \\
\hline 4 & A.C.T.H. & Slow & Subsided; no recurrence & Absent & Recurred & Absent & Present \\
\hline 5 & A.C.T.H. & Slow & $\begin{array}{l}\text { Present before admission; ab- } \\
\text { sent on admission; no recur- } \\
\text { rence }\end{array}$ & Recurred & Recurred & Absent & Absent \\
\hline 6 & A.C.T.H. & Rapid & $\begin{array}{l}\text { Present before admission; ab- } \\
\text { sent on admission; no recur- } \\
\text { rence }\end{array}$ & No recurrence & No recurrence & Absent & Absent \\
\hline 7 & A.C.T.H. & Rapid & Recurred & Absent & Recurred & Absent & Absent \\
\hline 8 & $\begin{array}{l}\text { A.C.T.H. and } \\
\text { Cortisone }\end{array}$ & $\underset{\text { Rlow }}{\text { Rapid-relapse }}$ & Subsided; no recurrence & No recurrence & Recurred & Absent & Absent \\
\hline 9 & Cortisone & Slow & Subsided; no recurrence & Absent & Recurred & Absent & Present \\
\hline
\end{tabular}

during the first 24 hours of treatment. Three developed it during, or shortly after concluding, hormone therapy. This course is not different from that seen in untreated cases. Nephritis, if it developed, was not appreciably influenced by treatment, and so the hormones were valueless in preventing or treating this complication.

It is concluded that A.C.T.H. and cortisone were of no value in treating our cases of the SchoenleinHenoch syndrome. Their use should probably be considered only in cases with a severe constitutional disturbance.

\section{Summary}

Nine cases of the Schoenlein-Henoch syndrome are presented in which treatment with A.C.T.H. and/or cortisone was given. No dramatic results were encountered. The drugs did not prevent relapses in the condition the onset of nephritis in three of seven cases, neither did they have any effect on the course of the nephritis. We were not convinced that the drugs were of any value in our cases.

We wish to thank Professor R. S. Illingworth and Professor E. J. Wayne for allowing us to study cases under their care, and for their helpful criticism and advice.

\section{REFERENCES}

Gairdner, D. (1948). Quart. J. Med., n.s. 17. 95.

Kugelmass, I. N. (1951). N.Y.St. J. Med., 51, 2504.

Philpott, M. G. (1952). Archives of Disease in Childhood, 27, 480.

Stefanini, M., Roy, C. A., Zannos, L. and Dameshek, W. (1950). $J$. Amer. med. Ass., 144, 1372

Woolley, E. J. S. (1952). Brit. med. J., I, 259. 